\title{
Prevalence of Low-Value Care and Its Associations with Patient-Centered Outcomes in Dementia
}

\author{
Moritz Platen ${ }^{\mathrm{a}}$, Steffen Fleßa ${ }^{\mathrm{b}}$, Anika Rädke ${ }^{\mathrm{a}}$, Diana Wucherer ${ }^{\mathrm{a}}$, Jochen René Thyrian ${ }^{\mathrm{a}, \mathrm{c}}$, \\ Wiebke Mohra ${ }^{\mathrm{a}}$, Annelie Scharfa ${ }^{\mathrm{a}}$, Franka Mühlichen ${ }^{\mathrm{a}}$, \\ Wolfgang Hoffmann ${ }^{\mathrm{a}, \mathrm{c}}$ and Bernhard Michalowsky,* \\ ${ }^{a}$ German Center for Neurodegenerative Diseases (DZNE), site Rostock/Greifswald, Greifswald, Germany \\ ${ }^{\mathrm{b}}$ Department of General Business Administration and Health Care Management, University of Greifswald, \\ Greifswald, Germany \\ ${ }^{\mathrm{c}}$ Institute for Community Medicine, Section Epidemiology of Health Care and Community Health, \\ University Medicine Greifswald (UMG), Greifswald, Germany
}

Handling Associate Editor: Anders Wimo

Accepted 30 July 2021

Pre-press 24 August 2021

\begin{abstract}
.
Background: Low-value care $(\mathrm{LvC})$ is defined as care unlikely to provide a benefit to the patient regarding the patient's preferences, potential harms, costs, or available alternatives. Avoiding LvC and promoting recommended evidence-based treatments, referred to as high-value care $(\mathrm{HvC})$, could improve patient-reported outcomes for people living with dementia (PwD).

Objective: This study aims to determine the prevalence of $\mathrm{LvC}$ and $\mathrm{HvC}$ in dementia and the associations of $\mathrm{LvC}$ and $\mathrm{HvC}$ with patients' quality of life and hospitalization.

Methods: The analysis was based on data of the DelpHi trial and included 516 PwD. Dementia-specific guidelines, the "Choosing Wisely" campaign and the PRISCUS list were used to indicate LvC and HvC treatments, resulting in $347 \mathrm{LvC}$ and $\mathrm{HvC}$ related recommendations. Of these, 77 recommendations ( 51 for $\mathrm{LvC}, 26$ for $\mathrm{HvC}$ ) were measured within the DelpHi-trial and finally used for this analysis. The association of $\mathrm{LvC}$ and $\mathrm{HvC}$ treatments with $\mathrm{PwD}$ health-related quality of life (HRQoL) and hospitalization was assessed using multiple regression models.

Results: $\mathrm{LvC}$ was highly prevalent in $\mathrm{PwD}(31 \%)$. PwD receiving $\mathrm{LvC}$ had a significantly lower quality of life $(b=-0.07$; $95 \% \mathrm{CI}-0.14-0.01)$ and were significantly more likely to be hospitalized ( $\mathrm{OR}=2.06$; 95\% CI 1.26-3.39). Different $\mathrm{HvC}$ treatments were associated with both positive and negative changes in HRQoL.

Conclusion: LvC could cause adverse outcomes and should be identified as early as possible and tried to be replaced. Future research should examine innovative models of care or treatment pathways supporting the identification and replacement of $\mathrm{LvC}$ in dementia.
\end{abstract}

Keywords: Alzheimer's disease, health-related quality of life, hospitalization, low-value care, patient-centered outcomes

\footnotetext{
${ }^{*}$ Correspondence to: Bernhard Michalowsky, German Center for Neurodegenerative Diseases (DZNE), site Rostock/Greifswald, Ellernholzstrasse 1-2, Greifswald D-17489, Germany. Tel.: +49 383442085 30; E-mail: bernhard.michalowsky@dzne.de.
} 


\section{INTRODUCTION}

Population aging is one of the challenges health systems face globally. This is associated with an increase in the prevalence of people suffering from dementia [1]. The World Alzheimer Report 2019 estimated that more than 50 million people live with dementia (PwD) worldwide. Within the next 30 years, the number of patients is predicted to reach 152 million, representing a considerable societal and economic burden [2]. The cost of dementia is estimated to be over US $\$ 1$ trillion worldwide, and this figure could double by $2030[2,3]$.

Rapidly increasing healthcare expenditures are likewise a global problem. While most of these expenditures are caused by demographic changes, new treatment possibilities, and increasing demand, Shrank et al. [4] estimated that the total annual costs of waste were $\$ 760$ billion to $\$ 935$ billion, representing $25 \%$ of total healthcare spending. Wasted health expenditures are mainly driven by failures in care delivery and coordination, pricing failures, fraud, abuse, and also overtreatment, as well as lowvalue care $(\mathrm{LvC})$ defined as care unlikely to provide a benefit to the patient regarding the patient's preferences, potential harms, costs, or available alternatives [5-7]. The study of Shrank et al. [4] revealed that LvC caused $\$ 75.7$ to $\$ 101.2$ billion annually in the US.

Overdiagnosis and overtreatment, as well as overtesting, and LvC are overlapping concepts addressing medical overuse along the entire care pathway [8]. As Elsaugh et al. [6] pointed out, freeing resources devoted to LvC could satisfy unmet health needs within the same budget. Related evidence gaps have been addressed in the research agenda for medical overuse [9]. Accordingly, evidence for effects and potential harms at the patient level is needed. Previous LvC-related studies have focused mainly on tests or nondrug procedures, using routinely collected data that represent the clinician's perspective $[10,11]$. Concerning drug treatments, this approach covers prescribing behavior, but findings addressing downstream patient-level effects of these low-value prescribing practices are rare.

In contrast, high-value care $(\mathrm{HvC})$ provides a benefit under consideration of all the mentioned aspects that define $\mathrm{LvC}$ [12]. However, it is difficult to distinguish between inappropriate and adequate health care service provision [13]. For this purpose, guidelines are providing support by issuing recommendations for or against health services representing over- and underuse or already established concepts by listing potentially inadequate medication [14-16].

PwD are a vulnerable multimorbid population that needs to receive $\mathrm{HvC}$ to delay the progression of cognitive decline, increase or maintain health-related quality of life (HRQoL) and live as long as possible community dwelling [17-19]. However, studies have revealed that PwD rarely receive evidence-based treatment and care according to guidelines [20]. Only $39 \%$ of people with positive dementia screening in primary care received a formal diagnosis at all, only $30 \%$ of PwD were provided with anti-dementia drugs, and $36 \%$ were provided with nondrug therapies, as recommended by guidelines [21-24]. Additionally, Amann et al. [25] showed that up to a quarter of elderly individuals receive potentially inadequate drugs. A recent study has shown that $93 \%$ of PwD had at least one drug-related problem, representing one part of LvC, which further leads to increased healthcare cost [26]. It is known that for elderly individuals and PwD, the likelihood of receiving LvC increases with age, higher comorbidity, and higher deficits in their daily living $[11,27]$.

Reducing LvC could simultaneously lead to greater efficiency in the healthcare system and higher value for patient-centered outcomes [28]. However, a recent survey with general practitioners (GPs) revealed that $\mathrm{LvC}$ is highly present in routine care [29]. The increasing number of PwD and the associated increasing socioeconomic burden of disease lead to a need to identify and replace $\mathrm{LvC}$ within routine care efficiently.

Previous research on $\mathrm{LvC}$ in dementia has focused on the frequency and its associated sociodemographic and clinical factors, as well as on its potential reduction $[11,27,30]$. Studies that consider both LvC and $\mathrm{HvC}$ at the same time to examine their respective associations with patient-reported outcomes, such as quality of life, or data, such as hospitalizations, are currently missing. Therefore, this study aims to demonstrate the prevalence of $\mathrm{LvC}$ and $\mathrm{HvC}$ treatments as well as to examine the associations between $\mathrm{LvC}$ and $\mathrm{HvC}$ treatments and patient-centered outcomes using data on community-dwelling PwD.

\section{MATERIALS METHODS}

\section{The DelpHi-trial}

\section{Design and participant flow}

The cross-sectional analysis used the baseline data of the cluster-randomized, controlled interventional 


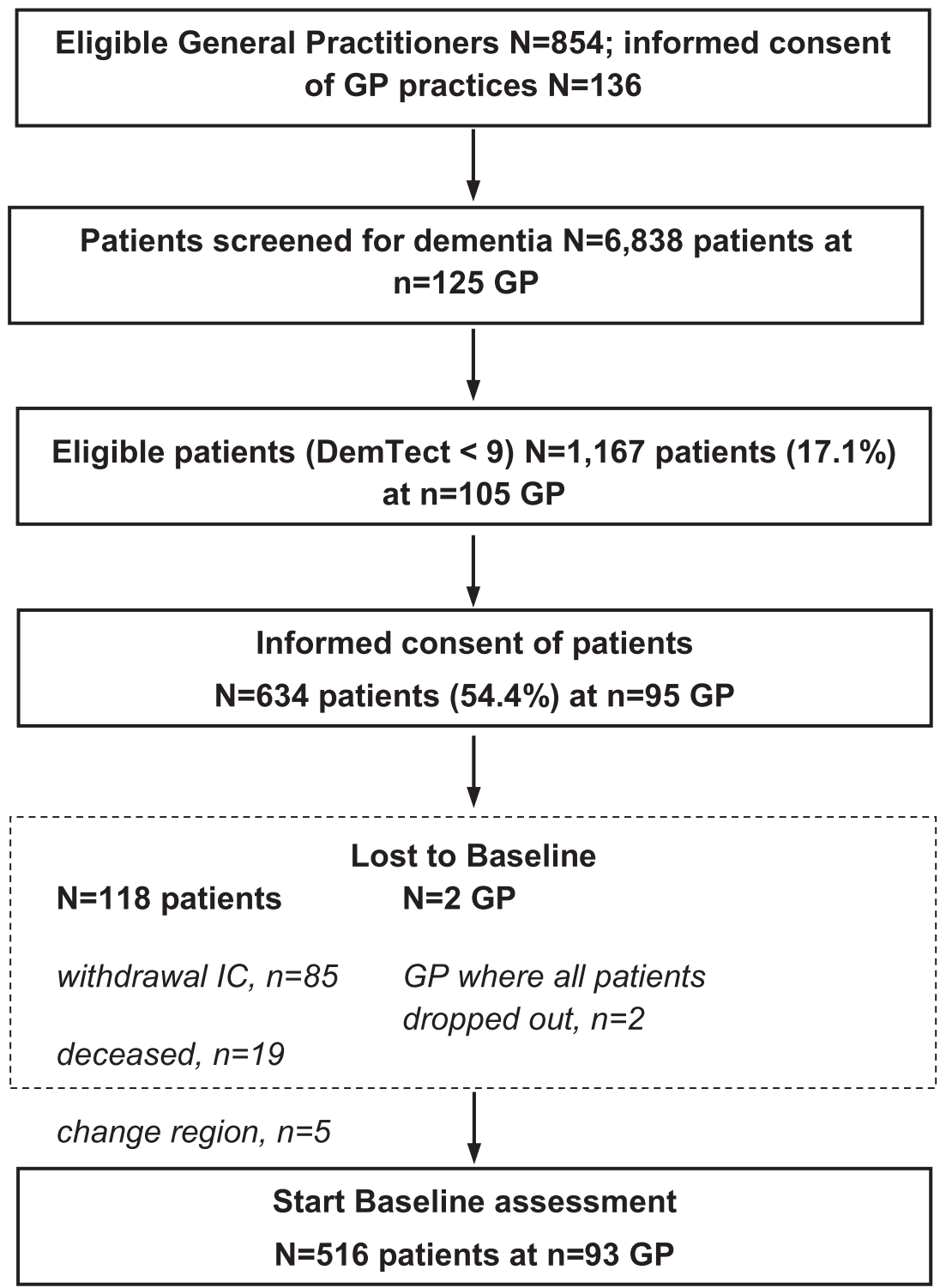

\section{IC, Written Informed Consent; GP, General Practitioner}

Fig. 1. DelpHi-trial flowchart.

DelpHi trial [31]. A total of 125 GP practices in Mecklenburg-Western Pomerania (state of Germany) screened 6,838 patients ( $\geq 70$ years, living at home) for dementia using the short interview-based DemTect procedure [32], which is more suitable and sensitive than the Mini-Mental State Examination [33] to detect early stages of dementia [34]. The eligibility criteria $($ DemTect $<9)$ were met by a total of $1,166(17 \%)$ patients who were subsequently informed about the study by the GP and asked for written informed consent. In total, 634 (54\%) persons agreed to participate in the trial. Of these, 516 patients completed the baseline assessment, representing the data basis of this analysis. The Ethics Committee of the Chamber of Physicians of Mecklenburg-Western Pomerania approved both the study protocol and documents for written IC (registry number BB 20/11). The design of the trial can be found in the study protocol [31]. Figure 1 shows the flow chart of the study up to the baseline assessment. 


\section{Sociodemographic and clinical data}

Sociodemographic data (age, sex) and the following clinical variables were assessed within the baseline assessment carried out by dementia-specific qualified nurses, so-called dementia care managers: cognitive impairment according to the Mini-Mental State Examination (MMSE) [33], comorbidity according to the number of ICD-10 (International Statistical Classification of Diseases and Related Health Problems, 10th revision) diagnoses listed in the GP files [35], depression symptoms according to the Geriatric Depression Scale (GDS) [36] and deficits in daily living activities according to the Bayer Activities of Daily Living Scale (B-ADL) [37].

\section{Patient-reported outcomes and data measures}

HRQoL was assessed using the Quality of LifeAD (QoL-AD) [38] and the 12-Item Short-Form Health Survey (SF-12) [39]. The dementia-specific QoL-AD is the most commonly used health-related quality of life questionnaire in dementia with good psychometric properties [38]. The QoL-AD includes 13 items with a four-point Likert scale. The total score ranges between 13 and 52, indicating very low and very high HRQoL, respectively [19, 38]. The $\mathrm{SF}-12$ is a generic, multidimensional instrument that measures the physical dimensions (SF-12-PCS) of HRQoL concerning the perception of general health, physical functioning, bodily pain, and role limitations due to the physical health state, as well as mental dimensions (SF-12-MCS) including social functioning, mental health, and vitality and role limitations due to emotional state [39]. The SF-12 is valid as a health status instrument in large community-based studies of older people and suitable for mildly to moderately cognitively impaired PwD [40, 41]. We further assessed patient hospitalization as patient-reported data in terms of whether the PwD had an acute or planned hospital stay (dichotomous: yes/no) within the last 12 months, using proxy ratings provided by caregivers to ensure the validity of the response [19].

\section{Low- and high-value care measures}

To indicate $\mathrm{LvC}$ and $\mathrm{HvC}$ treatments, the following three sources were used. We used the German "S3 guideline: Dementia" published by the German Association for Psychiatry, Psychotherapy and Psychosomatics and the German Society for Neuroscience, selecting treatments, procedures, and drugs that are effective, helpful, and highly recommended in their use (representing $\mathrm{HvC}$ ) or should be omitted or avoided (representing LvC) [15]. Additionally, defined positive and negative recommendations of the international "Choosing Wisely" campaign were used to identify further LvC and HvC treatments [14]. Finally, we used the PRISCUS list, comprising a total of 83 substances of 18 drug classes that are potentially inadequate for older people. This list includes recommendations $(\mathrm{LvC})$ and alternatives $(\mathrm{HvC})$, representing a decision-making aid [16].

The recommendations in all three sources were reviewed by two and, in case of deviation, by three independent reviewers. The selection was made after a discussion according to these criteria: relevance, targeted audience, differentiation possibilities, and existence in the data set used for this analysis, according to previous studies [42]. A total of $270(77.8 \%)$ out of 347 recommendations of the three independent sources had to be excluded because they did not meet the mentioned criteria (relevance (38.9\%), targeted audience $(1.4 \%)$, differentiation possibilities $(19.6 \%)$, and data capture $(17.9 \%))$. Of the remaining $77(22.2 \%)$ measurable recommendations, $51(14.7 \%)$ recommendations could be assigned to LvC and $26(7.5 \%)$ to HvC. Due to duplications and overlap, recommendations were broken down into individual components and grouped into measurable treatments, consistent with previous studies [10]. In conclusion, 14 measurable LvC and 11 measurable $\mathrm{HvC}$ treatments provided the basis for this analysis. The recommendations could also be divided into drug and nondrug recommendations. Following the PRISCUS list, the individual substances were grouped according to their drug classes. LvC treatments were completely drug-based, including a high proportion of inappropriate drugs. The selection process and all $\mathrm{LvC}$ and $\mathrm{HvC}$ measures are demonstrated in Supplementary Figure 1 and Table 2, respectively.

\section{Statistical analysis}

The study participants' sociodemographic and clinical characteristics and the prevalence of $\mathrm{LvC}$ and $\mathrm{HvC}$ treatments were presented using descriptive statistics. To identify patterns in clinical characteristics and to analyze the isolated effects of $\mathrm{LvC}$ and $\mathrm{HvC}$ on patient-reported outcomes, patients were categorized into the following groups: 1) receiving only $\mathrm{HvC}$ or 2) $\mathrm{LvC}, 3$ ) both $\mathrm{HvC}$ and $\mathrm{LvC}$, or 4) none of the measurable treatments. Differences between these respective treatment groups were assessed using $t$-tests, Fisher exact tests, Pearson's chi-squared test, and one-way analyses of variance 
added by the Scheffé test. To assess the associations of $\mathrm{LvC}$ and $\mathrm{HvC}$ and patient-reported outcomes, multivariable regression models with random effects for the GP were fitted. Outcomes such as HRQoL (QoL-AD, SF-12-MCS, SF-12-PCS) and the probability of hospitalization (dichotomous: yes/no) were used as dependent variables, and $\mathrm{LvC}$ and $\mathrm{HvC}$ treatments were used as independent variables in separate models. To minimize confounding, models were adjusted for the following sociodemographic and clinical factors: age, sex, cognition (MMSE), functional impairment (B-ADL), and depression (GDS). In addition, Charlson Comorbidity Index (CCI) [43] diagnoses were included in the adjustment to consider the context in which treatments were prescribed. In separate models, $\mathrm{LvC}$ and $\mathrm{HvC}$ treatments were further summed dichotomously (no $\mathrm{LvC} / \mathrm{HvC}$ versus at least one $\mathrm{LvC} / \mathrm{HvC}$ ) to assess the association of the overall $\mathrm{LvC}$ and $\mathrm{HvC}$ with the patientreported outcomes. Linear regression models were used for metric patient-reported outcomes (HRQoL), and logistic regression models were used for dichotomous patient-reported data (hospitalization: yes/no). All statistical analyses were performed in STATA/IC 15 [44].

\section{RESULTS}

\section{Sociodemographic and clinical characteristics}

The study participants were on average 80 years old, mostly female, and were mildly cognitively and functionally impaired according to the MMSE and the B-ADL, respectively. There were no statistical differences between patients assessed at baseline $(n=516)$ and those who dropped out before follow-up $(n=116)$ in age, sex, and DemTect score. Regarding the subsamples, PwD who received only $\mathrm{LvC}$ and no $\mathrm{HvC}$ treatments had on average a significantly lower cognitive impairment according to the MMSE and lower functional impairment according to the BADL compared to PwD who received only $\mathrm{HvC}$ and no LvC treatments. There were no significant differences for any of the other variables. The sample characteristics are presented in Table 1.

\section{Prevalence of low- and high-value care treatments}

159 PwD (31\%) received $\mathrm{LvC}$ treatments. These patients were more likely to be female $(65 \%$ versus $35 \%$ male). Those who received only $\mathrm{LvC}$ treatments were significantly less cognitively and functionally impaired than PwD, who received only $\mathrm{HvC}, \mathrm{LvC}$ and $\mathrm{HvC}$, or neither treatment. A total of $79 \%$ of PwD $(n=126)$ received exactly one $\mathrm{LvC}$ treatment, and $21 \%(n=33)$ received at least two. Approximately $73 \%$ of the LvC treatments $(n=141)$ concerned lowvalue antiphlogistics and analgesics, sedatives, and hypnotics as well as antidepressants and the use of memantine that does not comply with the guidelines.

In 194 PwD (38\%), HvC treatments were present. $\mathrm{PwD}$ who received $\mathrm{HvC}$ treatments had, on average, significantly lower cognitive functions, more deficits in daily living activities, and a higher HRQoL than patients who received $\mathrm{LvC}$ alone or in addition. Seventy-four percent of $\operatorname{PwD}(n=144)$ obtained exactly one $\mathrm{HvC}$ treatment, and $26 \%$ obtained at least two treatments $(n=50)$. A total of $72 \%$ of the recommended $\mathrm{HvC}$ treatments $(n=188)$ involve the use of high-value antiphlogistics and analgesics, antidementia drugs, antipsychotics, and antidepressants. Occupational therapy had the highest proportion of nondrug treatments among $\mathrm{HvC}$ therapies, at 5\% $(n=13)$. Table 2 displays the frequency of the respective $\mathrm{LvC}$ and $\mathrm{HvC}$ treatments. Table 3 summarizes the findings for sex, means, and mean differences of clinical characteristics by treatment groups, and the frequencies per case are shown in Supplementary Table 1.

\section{Associations between low- and high-value care treatments and patient-centered outcomes}

The multivariate regression analyses revealed that PwD who received LvC treatments had a significantly lower HRQoL, represented by a lower QoL-AD score $(B=-0.07 ; 95 \%$ CI $-0.14-0.01)$. After analyzing the treatments separately, sedatives and hypnotics $(B=-0.19$; 95\% CI $-0.32-0.06)$, which include benzodiazepines such as diazepam, clobazam, and medazepam, were also associated with a significantly lower QoL-AD score. PwD who received the antidementia drug memantine were associated with a significantly higher HRQoL with both recommended $(B=0.14 ; 95 \%$ CI $0.01-0.27)$ and non-recommended ( $B=0.17 ; 95 \%$ CI $0.01-0.32)$ use according to the guideline. However, findings varied by treatment in terms of mental and physical health status, represented by different SF-12 scores. $\mathrm{PwD}$ who received high-value antidepressants $(B=-$ 4.74; 95\% CI -8.08-1.41) such as sertraline or mirtazapine and likewise those who received either inadequate or guideline-based antiphlogistic 
Table 1

Socio-demographic and clinical characteristics of the total sample and subsamples

\begin{tabular}{|c|c|c|c|c|}
\hline & $\begin{array}{c}\text { Total sample } \\
n=516\end{array}$ & $\begin{array}{c}\text { Subsample LvC* } \\
n=159\end{array}$ & $\begin{array}{c}\text { Subsample } \mathrm{HvC}^{\dagger} \\
n=194\end{array}$ & $p$ \\
\hline \multicolumn{5}{|l|}{ Age } \\
\hline Mean (SD) & $80.0(5.5)$ & $79.3(5.5)$ & 80.3 (5.4) & \multirow[t]{2}{*}{$0.051^{\ddagger}$} \\
\hline Range & $70-100$ & $70-96$ & $70-94$ & \\
\hline \multicolumn{5}{|l|}{ Sex, n $(\%)$} \\
\hline Female & $307(59.50)$ & $104(65.41)$ & $124(63.92)$ & $0.527^{\S}$ \\
\hline \multicolumn{5}{|l|}{ MMSE } \\
\hline Mean (SD) & $22.2(5.4)$ & $23.0(4.4)$ & $20.4(5.8)$ & \multirow[t]{2}{*}{$\mathbf{0 . 0 0 1}$} \\
\hline Range & $3-30$ & $8-30$ & $5-30$ & \\
\hline \multicolumn{5}{|c|}{ Severity of dementia, n (\%) } \\
\hline No hint for dementia & $108(22.69)$ & $33(21.02)$ & $21(11.29)$ & \\
\hline Mild dementia & $239(50.21)$ & $94(59.87)$ & $87(46.77)$ & \\
\hline Moderate dementia & $107(22.48)$ & $27(17.20)$ & $62(33.33)$ & \\
\hline Severe dementia & $22(4.62)$ & $3(1.91)$ & $16(8.60)$ & \\
\hline \multicolumn{5}{|l|}{ B-ADL } \\
\hline Mean (SD) & $3.70(2.57)$ & $3.55(2.33)$ & $4.59(2.78)$ & \multirow[t]{2}{*}{$\mathbf{0 . 0 0 1}$} \\
\hline Range & $1-10$ & $1-10$ & $1-10$ & \\
\hline \multicolumn{5}{|l|}{ GDS } \\
\hline Mean (SD) & $3.17(2.46)$ & $3.52(2.80)$ & $3.37(2.48)$ & \multirow[t]{2}{*}{$0.576^{\ddagger}$} \\
\hline Range & $0-14$ & $0-14$ & $0-12$ & \\
\hline \multicolumn{5}{|c|}{ Number of ICD-10 diagnoses } \\
\hline Mean (SD) & $13.16(7.75)$ & $13.67(7.27)$ & $13.38(7.83)$ & \multirow[t]{2}{*}{$0.854^{\ddagger}$} \\
\hline Range & $1-58$ & $3-36$ & $1-36$ & \\
\hline \multicolumn{5}{|l|}{ QoL-AD } \\
\hline Mean (SD) & $2.70(0.58)$ & $2.66(0.57)$ & $2.62(0.71)$ & \multirow[t]{2}{*}{$0.419^{\ddagger}$} \\
\hline Range & $0-3.62$ & $0-3.62$ & $0-3.54$ & \\
\hline \multicolumn{5}{|l|}{ SF-12 (physical) } \\
\hline Mean (SD) & $41.81(10.51)$ & $39.85(10.17)$ & $40.78(10.88)$ & \multirow[t]{2}{*}{$0.453^{\ddagger}$} \\
\hline Range & $12.95-60.62$ & $12.95-58.12$ & $12.95-59.24$ & \\
\hline \multicolumn{5}{|l|}{ SF-12 (mental) } \\
\hline Mean (SD) & $52.92(9.88)$ & $52.44(11.26)$ & $52.12(10.27)$ & \multirow[t]{2}{*}{$0.648^{\ddagger}$} \\
\hline Range & $17.57-72.08$ & $17.57-72.08$ & $17.57-72.08$ & \\
\hline
\end{tabular}

LvC, Low-value Care; HvC, High-value Care; MMSE, Mini-Mental State Examination, range 0-30, higher score indicates better cognitive function; B-ADL, Bayer-Activities of Daily Living Scale, range 0-10, lower score indicates better performance; GDS, Geriatric Depression Scale, sum score 0-15, score $\geq 6$ indicates depression; ICD, International Statistical Classification of Diseases and Related Health Problems; QoL-AD, Quality of Life in Alzheimer's Diseases, mean sum score 1-4, higher score indicates better quality of life, SF-12, Short Form Health Survey, range 0-100, higher score indicates better quality of life; SD, standard deviation. *Patients received at least one LvC treatment. ${ }^{\dagger}$ Patients received at least one $\mathrm{HvC}$ treatment. ${ }^{\ddagger}$ Differences in means: $T$-Test two-tailed referring to patients who received only $\mathrm{LvC}$ but no $\mathrm{HvC}$ or only $\mathrm{HvC}$ but no LvC. (overlaps were excluded). ${ }^{\S}$ Differences in proportions: Fisher's exact Tests referring to patients who received only $\mathrm{LvC}$ but no HvC or only $\mathrm{HvC}$ but no LvC. (overlaps were excluded).

or analgesic treatments $\left(\mathrm{B}^{\mathrm{LvC}}=-3.02\right.$ versus $\mathrm{B}^{\mathrm{HvC}}=$ -3.02) were associated with lower HRQoL.

Concerning hospitalization, receiving at least one LvC treatment was associated with significantly higher odds of hospitalization within the last 12 months $(\mathrm{OR}=2.06$; 95\% CI 1.26-3.39). In particular, low-value antihypertensives drugs were associated with higher odds of hospitalization $(\mathrm{OR}=4.18 ; 95 \%$ CI 1.19-14.65). Further, PwD treated with other lowvalue antidementia drugs such as piracetam were also more likely to be hospitalized (OR $=14.37 ; 95 \% \mathrm{CI}$ 2.64-78.16). There was no significant association between receiving at least one $\mathrm{HvC}$ treatment or a certain $\mathrm{HvC}$ treatment and the patient-reported outcomes or hospitalization data of PwD. Table 4 and Fig. 2 show the results for associations between $\mathrm{LvC}$ and $\mathrm{HvC}$ and patient-centered outcomes of $\mathrm{PwD}$.

\section{DISCUSSION}

This study aimed to examine the associations between $\mathrm{LvC}$ and $\mathrm{HvC}$ treatments and patient-reported outcomes and hospitalization data. One-third of community-dwelling $\mathrm{PwD}$ received $\mathrm{LvC}$ treatments, 
Table 2

Frequency of LvC and $\mathrm{HvC}$ treatments

\begin{tabular}{|c|c|c|c|}
\hline $\begin{array}{l}\text { Low-value Care }(n=194) \\
\text { Treatment - Drug class (included substances) }\end{array}$ & $n(\%)$ & $\begin{array}{l}\text { High-value Care }(n=260) \\
\text { Treatment - Drug class (included substances) }\end{array}$ & $n(\%)$ \\
\hline $\begin{array}{l}\text { Low-value antiphlogistics/ analgesics (Dexketoprofen, } \\
\text { etoricoxib, indometacin, meloxicam, naproxen, } \\
\text { diclofenac) }\end{array}$ & $59(30.41)$ & $\begin{array}{l}\text { High-value antiphlogistics/ analgesics (Paracetamol, } \\
\text { tramadol, codeine, ibuprofen) }\end{array}$ & $62(23.85)$ \\
\hline $\begin{array}{l}\text { Low-value Memantine does not complies with the } \\
\text { guidelines for mild dementia }\end{array}$ & $29(14.95)$ & $\begin{array}{l}\text { High-value other antidementia drugs (Donepezil, } \\
\text { galantamine, rivastigmine) }\end{array}$ & $51(19.62)$ \\
\hline $\begin{array}{l}\text { Low-value sedatives/ hypnotics (Chloral hydrate, } \\
\text { chlordiazepoxide, clobazam, diazepam, zopiclon, } \\
\text { diphenhydramine, doxylamine, medazepam, } \\
\text { nitrazepam, zolpidem) }\end{array}$ & $28(14.43)$ & $\begin{array}{l}\text { High-value antipsychotics (Risperidone, melperone, } \\
\text { pipamperone) }\end{array}$ & $38(14.62)$ \\
\hline $\begin{array}{l}\text { Low-value antidepressants (Amitriptyline, } \\
\text { amitriptylinoxide, doxepin, trimipramine) }\end{array}$ & $25(12.89)$ & $\begin{array}{l}\text { High-value antidepressants (Citalopram, escitalopram, } \\
\text { sertraline, mirtazapine, opipramol) }\end{array}$ & $37(14.23)$ \\
\hline $\begin{array}{l}\text { Low-value antihypertensives (Clonidine, doxazosin, } \\
\text { methyldopa) }\end{array}$ & $16(8.25)$ & $\begin{array}{l}\text { High-value Memantine (complies with the guidelines } \\
\text { for moderate to severe dementia) }\end{array}$ & $29(11.15)$ \\
\hline Low-value spasmolytics (Solifenacin, tolterodine) & $10(5.15)$ & $\begin{array}{l}\text { High-value occupational therapy (complies with the } \\
\text { guidelines for mild to moderate dementia) }\end{array}$ & $13(5.00)$ \\
\hline $\begin{array}{l}\text { Low-value other antidementia drugs (Naftidrofuryl, } \\
\text { piracetam, dihydroergotoxine) }\end{array}$ & $8(4.12)$ & High-value spasmolytics (Trospium) & $13(5.00)$ \\
\hline $\begin{array}{l}\text { Low-value antiarrhythmics (Acetyldigoxin, flecainide, } \\
\text { sotalol) }\end{array}$ & $4(2.06)$ & $\begin{array}{l}\text { High-value antiemetics (Domperidone, } \\
\text { metoclopramide) }\end{array}$ & $12(4.62)$ \\
\hline Low-value muscle relaxants (Baclofen, tetrazepam) & $4(2.06)$ & High-value muscle relaxants (Tolperisone, tizanidine) & $2(0.77)$ \\
\hline $\begin{array}{l}\text { Low-value antipsychotics (Levomepromazine, } \\
\text { olanzapine, haloperidol) }\end{array}$ & $4(2.06)$ & High-value antiarrhythmics (Amiodarone) & $2(0.77)$ \\
\hline $\begin{array}{l}\text { Low-value antipsychotic (Quetiapin) (does not complies } \\
\text { with the guidelines for agitation and aggression) }\end{array}$ & $3(1.55)$ & $\begin{array}{l}\text { High-value psychotherapy (complies with the } \\
\text { guidelines for depression) }\end{array}$ & $1(0.38)$ \\
\hline Low-value antiemetics (Dimenhydrinate) & $2(1.03)$ & & \\
\hline Low-value ergotamine (Dihydroergocryptine) & $1(0.52)$ & & \\
\hline Low-value vitamin $\mathrm{E}$ & $1(0.52)$ & & \\
\hline
\end{tabular}

LvC, Low-value Care; HvC, High-value Care.

Table 3

Sex, means, and mean differences of clinical characteristics by treatment groups

\begin{tabular}{|c|c|c|c|c|c|c|c|c|c|}
\hline \multicolumn{10}{|c|}{ 3.1 Sex and means of clinical characteristics by treatment groups } \\
\hline Sex and clinical characteristics & & $\begin{array}{l}\mathrm{LvC}^{*} \\
n=102\end{array}$ & & $\begin{array}{l}\mathrm{HvC}^{*} \\
n=137\end{array}$ & & $\begin{array}{c}\mathrm{vC} \& \mathrm{HvC}^{\dagger} \\
n=57\end{array}$ & & $\begin{array}{l}\text { ither LvC } \\
\text { or } \mathrm{HvC}^{\dagger} \\
n=220\end{array}$ & $p$ \\
\hline Sex female, $n(\%)$ & 60 & $(58.82)$ & 80 & (58.93) & 44 & (77.19) & 123 & $(55.91)$ & $\mathbf{0 . 0 3 4}$ \\
\hline MMSE, $n$, mean (SD) & 101 & $23.62(4.16)$ & 127 & $19.71(6.16)$ & 54 & $21.94(4.67)$ & 187 & $23.10(5.01)$ & $<0.001^{\S}$ \\
\hline $\mathrm{B}-\mathrm{ADL}, n$, mean (SD) & 100 & $2.99(2.01)$ & 131 & $4.60(2.89)$ & 55 & $4.56(2.53)$ & 214 & $3.27(2.40)$ & $<0.001^{\S}$ \\
\hline GDS, $n$, mean $(\mathrm{SD})$ & 101 & $3.35(2.66)$ & 126 & $3.17(2.17)$ & 55 & $3.84(3.04)$ & 210 & $2.91(2.34)$ & $0.075^{\S}$ \\
\hline QoL-AD, $n$, mean (SD) & 102 & $2.71(0.45)$ & 136 & $2.64(0.70)$ & 57 & $2.57(0.73)$ & 215 & $2.77(0.49)$ & $0.050^{\S}$ \\
\hline SF-12 (physical), $n$, mean (SD) & 93 & $41.41(9.17)$ & 115 & $42.44(10.29)$ & 49 & $36.87(11.35)$ & 200 & $42.84(10.72)$ & $0.004^{\S}$ \\
\hline
\end{tabular}

3.2 Mean differences for clinical characteristics between the respective treatment groups ${ }^{\S}$

\begin{tabular}{llccccc}
\hline & & \multicolumn{3}{c}{ Mean difference $(p$ value $)$} \\
\cline { 3 - 7 } Patients receiving . . versus & Patients receiving ... & MMSE & B-ADL & GDS & QoL-AD & SF-12 (physical) \\
\hline only LvC & only HvC & $\mathbf{3 . 9 1}(\mathbf{0 . 0 0 0})$ & $\mathbf{- 1 . 6 1 ( 0 . 0 0 0 )}$ & $0.18(0.960)$ & $0.06(0.867)$ & $-1.03(0.918)$ \\
& both LvC and HvC & $1.68(0.292)$ & $\mathbf{- 1 . 5 7 ( 0 . 0 0 3 )}$ & $-0.49(0.702)$ & $0.14(0.538)$ & $4.54(0.106)$ \\
& neither LvC nor HvC & $0.53(0.876)$ & $-0.28(0.827)$ & $0.44(0.540)$ & $-0.07(0.822)$ & $-1.43(0.752)$ \\
only HvC & both LvC and HvC & $-2.23(0.071)$ & $0.04(1.000)$ & $-0.67(0.416)$ & $0.08(0.873)$ & $\mathbf{5 . 5 7}(\mathbf{0 . 0 2 0})$ \\
& neither LvC nor HvC & $\mathbf{- 3 . 3 8 ( \mathbf { 0 . 0 0 0 } )}$ & $\mathbf{1 . 3 2}(\mathbf{0 . 0 0 0})$ & $0.26(0.834)$ & $-0.13(0.235)$ & $-0.40(0.991)$ \\
both LvC and HvC & neither LvC nor HvC & $-1.15(0.554)$ & $\mathbf{1 . 2 9}(\mathbf{0 . 0 0 9})$ & $0.93(0.103)$ & $-0.21(0.124)$ & $\mathbf{- 5 . 9 8}(\mathbf{0 . 0 0 5})$ \\
\hline
\end{tabular}

LvC, Low-value Care; HvC, High-value Care; MMSE, Mini-Mental State Examination, range 0-30, higher score indicates better cognitive function; B-ADL, Bayer-Activities of Daily Living Scale, range 0-10, lower score indicates better performance; GDS, Geriatric Depression Scale, sum score 0-15, score $\geq 6$ indicates depression; QoL-AD, Quality of Life in Alzheimer's Diseases, mean sum score 1-4, higher score indicates better quality of life, SF-12, Short Form Health Survey, range 0-100, higher score indicates better quality of life; SD, standard deviation. *Patients who received only LvC but no $\mathrm{HvC}$ or only $\mathrm{HvC}$ but no LvC. ${ }^{\dagger}$ Patients who received both LvC and HvC or neither HvC nor LvC. ${ }^{\ddagger}$ Differences in proportions: Pearson’s chi-squared test; ${ }^{\S}$ Differences in means: oneway analysis of variance (ANOVA) with a Scheffé post hoc test. 
Table 4

Associations between $\mathrm{LvC}$ and $\mathrm{HvC}$ and patient-centered outcomes of $\mathrm{PwD}-\mathrm{HRQoL}$ and Hospitalization

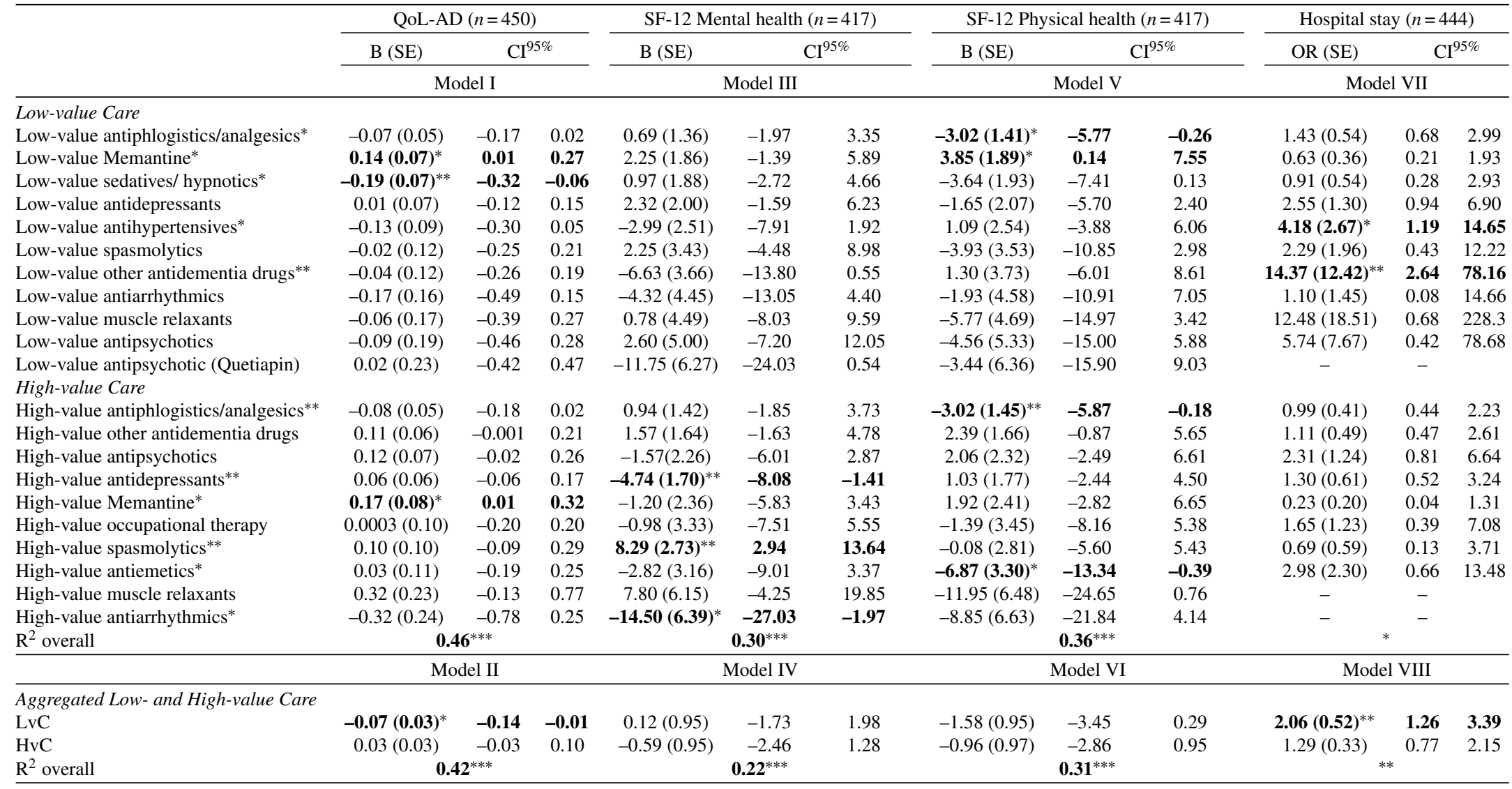

LvC, Low-value Care; HvC, High-value Care; PwD, People with Dementia; HRQoL, Health-Related Quality of Life; QoL-AD, Quality of Life in Alzheimer's Diseases, mean sum score 1-4, higher score indicates better quality of life; SF-12, Short Form Health Survey mental/physical dimension, range 0-100, higher score indicates better quality of life; OR, odds ratios; B, observed coefficient; SE, standard error; CI, confidence interval. ${ }^{*} p<0.05,{ }^{* *} p<0.01,{ }^{* * *} p<0.001$. The models used were adjusted for socio-demographic and clinical variables: age, sex, cognition (MMSE), functional impairment (B-ADL), depression (GDS), comorbidities (CCI). 

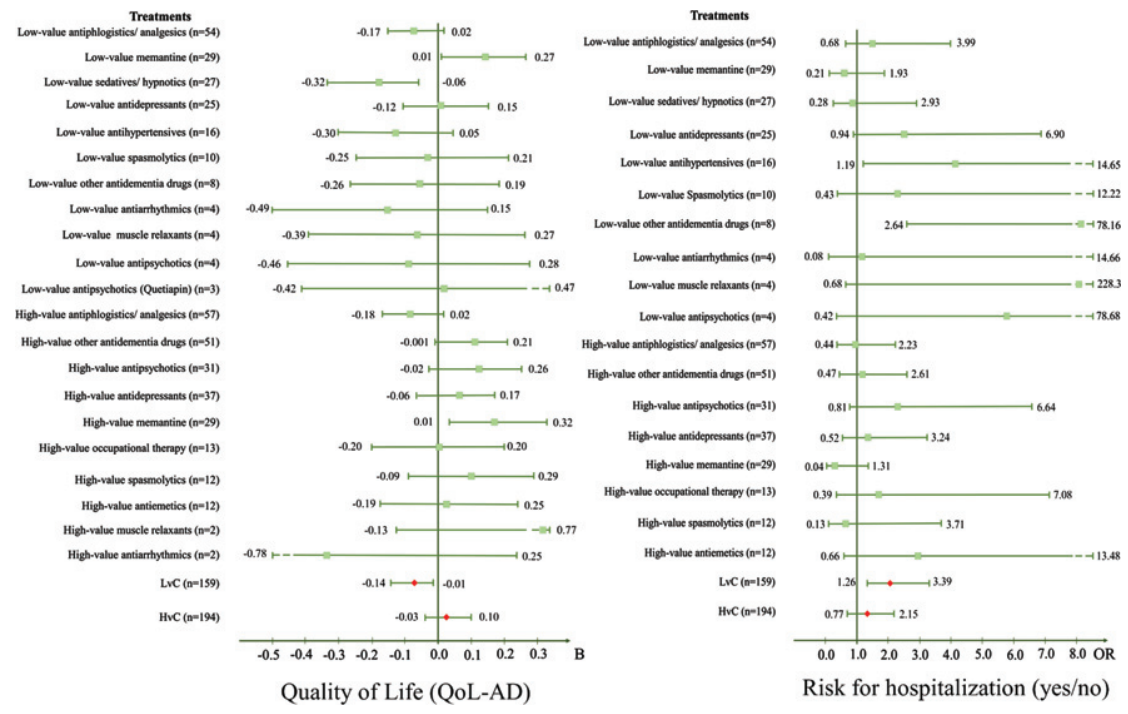

LvC, Low-value Care; HvC, High-value Care; PwD, People with Dementia; HRQol, Health-Related Quality of Life; QoL-AD, Quality of Life in

Alzheimer's Diseases, mean sum score 1-4, higher score indicates better quality of life; B, observed coefficient; OR, odds ratios

Fig. 2. Forest plots for the associations between $\mathrm{LvC}$ and $\mathrm{HvC}$ and patient-centered outcomes of PwD - QoL-AD and Hospitalization.

indicating that $\mathrm{LvC}$ was highly present in community-dwelling PwD. These patients were less functionally and cognitively impaired. $\mathrm{LvC}$ in $\mathrm{PwD}$ was mainly caused by drug therapies with lowvalue antiphlogistics and analgesics, sedatives, and hypnotics as well as antidepressants. Receiving at least one $\mathrm{LvC}$ treatment were associated with a lower HRQoL and an increased risk for hospitalization. $\mathrm{HvC}$ treatments were highly prevalent as well. However, the results show that recommended $\mathrm{HvC}$ services alone do not guarantee a positive patientreported outcome. Whereas a guideline-based prescription of memantine was associated with an increased HRQoL, the recommended therapy alternatives with antidepressant drugs were associated with a lower HRQoL.

Several studies have already focused on various harmful treatments and their risk factors among PwD $[11,27]$. According to these studies, the risk for receiving $\mathrm{LvC}$ is age-related and associated with a higher degree of comorbidity. In our data, there were no group differences in age and number of ICD10 diagnoses between patients receiving only $\mathrm{LvC}$ or $\mathrm{HvC}$ treatments. However, it is already known that PwD have, on average, higher comorbidity than elderly individuals without dementia, underlining that PwD are a high-risk group for receiving $\mathrm{LvC}$ [45]. Contrary to previous routine data-based studies, the conducted patient-level analysis identifies that
PwD who received LvC had fewer deficits in their activities of daily living and cognition than those who received $\mathrm{HvC}$, indicating potentially less mental and physical comorbidities. On the other hand, in this study, patients were included after an initial screening procedure. At the time point of the screening, only $39 \%$ of patients had a formal dementia diagnosis [21]. This rate increased after the screening to 70\% [46]. Hence, the systematic recruitment scheme increased the GPs' diagnostic attention, which may explain why our sample was less cognitively and functionally impaired than previous studies. Additionally, previous studies found that diagnosed cases were more often associated with severe MMSE scores and better anti-dementia drug treatment $[21,24]$, demonstrating earlier diagnosis could help to avoid $\mathrm{LvC}$ for PwD.

Considering $\mathrm{HvC}$ treatments, recent studies have shown that the probability of receiving care according to the guidelines for PwD depends on a patient's age, severity, and comorbidity, which is in line with the results of our study $[22,23]$. PwD who received $\mathrm{HvC}$ treatments had lower cognitive functions and were slightly older, even though the age differences were not statistically significant. Lower HRQoL and greater deficits in activities of daily living also indicate a higher degree of comorbidity. However, in this study, there was no measured correlation between the comorbidity of PwD and the presence of the respective treatment group. In conclusion, further 
studies are needed to evaluate the association of specific comorbidities and their respective single and combined impact on the presence of $\mathrm{LvC}$ and its downstream effects on patient-reported outcomes.

According to the research agenda on medical overuse [9], patient-level studies are needed to assess the harmful effects of overuse and to fill the research gap that results from studies based primarily on routine data. This conducted analysis revealed $\mathrm{LvC}$ could cause a lower HRQoL and is associated with a higher probability of hospitalization, providing findings of vital importance. The individual substance groups considered underscores these findings. The evidence for inappropriate antiphlogistics and analgesics show, there is no convincing evidence of efficacy against symptoms of Alzheimer's disease. Rather, these drugs are associated with an increased risk of gastrointestinal bleeding $[15,16]$. Inappropriate sedatives and hypnotics are mainly benzodiazepines. Among elderly individuals, and particularly those with dementia, benzodiazepines are associated with higher risks of falls and fractures that cause hospitalizations [14]. Finally, also for antidepressants, especially those with anticholinergic properties, studies have already shown that their use is associated with an increased risk of hospitalization $[47,48]$. Thus, our findings are in line with these studies.

Previous studies pointed out that the definitions of the respective $\mathrm{LvC}$ or $\mathrm{HvC}$ treatments vary in terms of specificity and sensitivity depending on the source used and the clinical context [13,49]. Therapy alternatives with antidepressant drugs, such as sertraline or mirtazapine, are designated by the PRISCUS list [16]. The evidence, however, is still ambiguous. A study revealed no superiority of prescription of these antidepressant drugs over placebo but an association with adverse events [50]. Our findings were in line with this study, underlining the uncertainties associated with antidepressants in the treatment of PwD. Concerning memantine, guidelines recommend a treatment in moderate to severe dementia to improve cognition and everyday function but advise against it in mild dementia since efficacy is not proven and refer to alternatives [15]. The analyses performed show that memantine is associated with higher HRQoL in both cases, illustrating that $\mathrm{LvC}$ depends on the context and perspective from which it is defined. These findings emphasize that $\mathrm{HvC}$ is not the simple opposite of $\mathrm{LvC}$ and vice versa and that the expert perspective may differ from what the patient wants. The adoption of $\mathrm{HvC}$ needs to consider the clinical context and the organization of health care provision. Rather than focusing on the quality of single treatments, dementia care seems to require a more comprehensive disease management approach [51].

The care of PwD is high-value if it considers patient preferences and reduces the negative outcomes caused by LvC. Hence, dementia care should be addressed by innovative care models or treatment approaches, especially regarding hospitalization for PwD. Baicker and Chandra highlighted that hospitalizations are key drivers of health expenditures and that policy reforms should be guided by whether they improve the allocation of resources in care [52]. Recent studies have suggested comprehensive care models or treatment pathways to reduce the utilization of $\mathrm{LvC}$ in primary care as well as to improve patient-reported outcomes, claiming that these would simultaneously reduce health expenditures $[17,53$, 54]. In times of increasing numbers of PwD and the growing socioeconomic burden on healthcare systems worldwide, innovative approaches and treatment strategies are of vital importance.

Cross-sectional data alone cannot establish cause and effect. It is possible that PwD with a lower HRQoL are treated with LvC; thus, HRQoL cannot be considered a consequence of the treatment. Further research should evaluate the observed associations of $\mathrm{LvC}$ and $\mathrm{HvC}$ with patient-reported outcomes in a longitudinal approach. There is also a need to identify relevant subgroups of PwD that could benefit most from canceling $\mathrm{LvC}$ treatments. We need to clarify whether the same subgroups or others would benefit the most from an increase in $\mathrm{HvC}$, especially nondrug treatments.

\section{Limitations}

This cross-sectional analysis was based on the baseline data of the DelpHi trial [31]. The data represent a mainly rural region of Germany, which may limit the generalizability of the presented results to more urban settings. Primary data, especially on outcomes, were obtained directly from the patients. Other sources, such as health insurance, were not available [55]. Given the clinical course of dementia, the completeness and correctness of information may be affected by the limited cognitive capacities of the patients. However, the majority of patients in our sample had mild cognitive impairment or earlystage dementia. To increase the validity of our data, we systematically solicited further information from nursing services and caregivers [22]. The participants 
of the study were on average 80 years old and were living community dwelling. Thus, we cannot generalize the findings to PwD living in institutions [26]. Additionally, the SF-12 is a practicable and adequate tool for assessing the HRQoL for PwD with an MMSE score greater than 16, but the study also included $40 \mathrm{PwD}$ with a score less than 16 , for whom the validity is restricted [17].

To directly measure LvC, clinical evidence-based guidelines and consensus-based expert publications were used, resulting in the following two limitations: First, the expert lens did not consider the patient perspective, such as LvC as unwanted care, and second, there is a lack of economic evidence in LvC recommendations, overemphasizing clinical rationales, as recently stated by Kim et al. [56]. Generally, the classification of treatment as $\mathrm{LvC}$ depends on the context of healthcare provision and, in particular, the diagnosis, which only $40 \%$ of PwD had at the time of the screening procedure before starting the baseline assessment. However, this proportion increased to $70 \%$ at the day of screening. Additional analyses revealed that the proportion of diagnosed PwD further increased the weeks after the screening procedure, still before starting the baseline assessment $[21,46]$. Furthermore, the LvC-related findings are limited to drug-associated treatments, particularly inappropriate drugs, and are nonapplicable to nondrug treatments, surgery, or diagnostic tests. As a result, due to the insufficient data, the prevalence of $\mathrm{LvC}$ is somewhat underestimated. Additionally, due to the low prevalence of some $\mathrm{LvC}$ or $\mathrm{HvC}$ treatments, some of the presented results are not generalizable and have to be confirmed in future research that is based on larger sample sizes.

\section{ACKNOWLEDGMENTS}

The DelpHi-trial was performed in cooperation with and funded by the German Center for Neurodegenerative Diseases and the University Medicine Greifswald. We acknowledge Aniela Angelow, Grit Aßmann, Georgia Böwing, Adina Dreier-Wofgramm, Thomas Fiß, Daniel Fredrich, Leonore Köhler, and Ina Zwingman. An experienced field study team provided support with data collection and data management: Ines Abraham, Kerstin Albuerne, Vaska Böhmann, Kathleen Dittmer, Sarah Gardzella, Jana Hubert, Ulrike Kempe, Viktoriya Kim, Julius Krause, Andrea Pooch, Saskia Moll, Melanie Reimann, Sabine Schmidt, and Christine
Winckler. We thank all participating patients and their caregivers as well as the participating general practitioners for their most valued collaboration.

Authors' disclosures available online (https:// www.j-alz.com/manuscript-disclosures/21-0439r1).

\section{SUPPLEMENTARY MATERIAL}

The supplementary material is available in the electronic version of this article: https://dx.doi.org/ 10.3233/JAD-210439.

\section{REFERENCES}

[1] Prince M, Guerchet M, Prina M (2015) The Epidemiology and Impact of Dementia - Current State and Future Trends. WHO Thematic Briefing. World Health Organization (WHO).

[2] Alzheimer's Disease International (2019) World Alzheimer Report 2019: Attitudes to Dementia, London.

[3] Wimo A, Guerchet M, Ali GC, Wu YT, Prina AM, Winblad B, Jönsson L, Liu Z, Prince M (2017) The worldwide costs of dementia 2015 and comparisons with 2010. Alzheimers Dement 13, 1-7.

[4] Shrank WH, Rogstad TL, Parekh N (2019) Waste in the US health care system: Estimated costs and potential for savings. JAMA 322, 1501-1509.

[5] Berwick DM, Hackbarth AD (2012) Eliminating waste in US health care. JAMA 307, 1513-1516.

[6] Elshaug AG, Rosenthal MB, Lavis JN, Brownlee S, Schmidt H, Nagpal S, Littlejohns P, Srivastava D, Tunis S, Saini V (2017) Levers for addressing medical underuse and overuse: Achieving high-value health care. Lancet 390, 191-202.

[7] Verkerk EW, Tanke MAC, Kool RB, van Dulmen SA, Westert GP (2018) Limit, lean or listen? A typology of low-value care that gives direction in de-implementation. Int J Qual Health Care 30, 736-739.

[8] Brownlee S, Chalkidou K, Doust J, Elshaug AG, Glasziou P, Heath I, Nagpal S, Saini V, Srivastava D, Chalmers K, Korenstein D (2017) Evidence for overuse of medical services around the world. Lancet 390, 156-168.

[9] Morgan DJ, Brownlee S, Leppin AL, Kressin N, Dhruva SS, Levin L, Landon BE, Zezza MA, Schmidt H, Saini V, Elshaug AG (2015) Setting a research agenda for medical overuse. BMJ 351, h4534.

[10] Brett J, Elshaug AG, Bhatia RS, Chalmers K, BadgeryParker T, Pearson SA (2017) A methodological protocol for selecting and quantifying low-value prescribing practices in routinely collected data: An Australian case study. Implement Sci 12, 58.

[11] Brett J, Zoega H, Buckley NA, Daniels BJ, Elshaug AG, Pearson SA (2018) Choosing wisely? Quantifying the extent of three low value psychotropic prescribing practices in Australia. BMC Health Serv Res 18, 1009.

[12] Owens DK, Qaseem A, Chou R, Shekelle P (2011) Highvalue, cost-conscious health care: Concepts for clinicians to evaluate the benefits, harms, and costs of medical interventions. Ann Intern Med 154, 174-180.

[13] Schwartz AL, Landon BE, Elshaug AG, Chernew ME, McWilliams JM (2014) Measuring low-value care in Medicare. JAMA Intern Med 174, 1067-1076. 
[14] Deutsche Gesellschaft für Innere Medizin e.V. (2019) Sammelband Initiative "Klug Entscheiden". Deutsches Ärzteblatt.

[15] Deutsche Gesellschaft für Psychiatrie Psychotherapie und Nervenheilkunde und Deutsche Gesellschaft für Neurologie (2017) S3-Leitlinie Demenzen, Springer-Verlag, Berlin, Heidelberg.

[16] Holt S, Schmiedl S, Thürmann PA (2010) Potenziell inadäquate Medikation für ältere Menschen. Dtsch Arztebl Int 107, 543-551.

[17] Michalowsky B, Xie F, Eichler T, Hertel J, Kaczynski A, Kilimann I, Teipel S, Wucherer D, Zwingmann I, Thyrian JR, Hoffmann W (2019) Cost-effectiveness of a collaborative dementia care management-Results of a cluster-randomized controlled trial. Alzheimers Dement 15, 1296-1308.

[18] Robinson L, Tang E, Taylor J-P (2015) Dementia: Timely diagnosis and early intervention. BMJ 350, h3029.

[19] Thyrian JR, Eichler T, Michalowsky B, Wucherer D, Reimann M, Hertel J, Richter S, Dreier A, Hoffmann W (2016) Community-dwelling people screened positive for dementia in primary care: A comprehensive, multivariate descriptive analysis using data from the DelpHi-Study. $J$ Alzheimers Dis 52, 609-617.

[20] Vickrey BG, Mittman BS, Connor KI, Pearson ML, Della Penna RD, Ganiats TG, Demonte RW, Jr., Chodosh J, Cui X, Vassar S, Duan N, Lee M (2006) The effect of a disease management intervention on quality and outcomes of dementia care: A randomized, controlled trial. Ann Intern Med 145, 713-726.

[21] Eichler T, Thyrian JR, Hertel J, Köhler L, Wucherer D, Dreier A, Michalowsky B, Teipel S, Hoffmann W (2014) Rates of formal diagnosis in people screened positive for dementia in primary care: Results of the DelpHi-Trial. $J$ Alzheimers Dis 42, 451-458.

[22] Michalowsky B, Flessa S, Eichler T, Hertel J, Dreier A, Zwingmann I, Wucherer D, Rau H, Thyrian JR, Hoffmann W (2018) Healthcare utilization and costs in primary care patients with dementia: Baseline results of the DelpHi-trial. Eur J Health Econ 19, 87-102.

[23] Wübbeler M, Thyrian JR, Michalowsky B, Hertel J, Laporte Uribe F, Wolf-Ostermann K, Schäfer-Walkmann S, Hoffmann W (2015) Nonpharmacological therapies and provision of aids in outpatient dementia networks in Germany: Utilization rates and associated factors. J Multidiscip Healthc 8, 229-236.

[24] Wucherer D, Eichler T, Kilimann I, Hertel J, Michalowsky B, Thyrian JR, Teipel S, Hoffmann W (2015) Antidementia drug treatment in people screened positive for dementia in primary care. J Alzheimers Dis 44, 1015-1021.

[25] Amann U, Schmedt N, Garbe E (2012) Ärztliche Verordnungen von potenziell inadäquater Medikation bei Älteren. Dtsch Arztebl Int 109, 69-75.

[26] Wohlgemuth A, Michalowsky B, Wucherer D, Eichler T, Thyrian JR, Zwingmann I, Rädke A, Hoffmann W (2020) Drug-related problems increase healthcare costs for people living with dementia. J Alzheimers Dis 73, 791-799.

[27] Nili M, Shen C, Sambamoorthi U (2020) Low-value care: Antipsychotic medication use among community-dwelling Medicare beneficiaries with Alzheimer's disease and related dementias and without severe mental illness. Aging Ment Health 24, 504-510.

[28] Badgery-Parker T, Pearson SA, Chalmers K, Brett J, Scott IA, Dunn S, Onley N, Elshaug AG (2019) Low-value care in Australian public hospitals: Prevalence and trends over time. BMJ Qual Saf 28, 205-214.
[29] Kool RB, Verkerk EW, Winnemuller LJ, Wiersma T, Westert GP, Burgers JS, van Dulmen SA (2020) Identifying and de-implementing low-value care in primary care: The GP's perspective-a cross-sectional survey. BMJ Open 10, e037019.

[30] Scott IA, Duckett SJ (2015) In search of professional consensus in defining and reducing low-value care. Med J Aust 203, 179-181.

[31] Thyrian JR, Fiß T, Dreier A, Böwing G, Angelow A, Lueke S, Teipel S, Fleßa S, Grabe HJ, Freyberger HJ, Hoffmann W (2012) Life- and person-centred help in MecklenburgWestern Pomerania, Germany (DelpHi): Study protocol for a randomised controlled trial. Trials $13,56$.

[32] Calabrese P, Kessler J (2000) Screening for cognitive impairment in dementia - the DemTect procedure. Eur Neuropsychopharmacol 10, 369.

[33] Kessler J, Markowitsch H, Denzler P (1990) Mini-MentalStatus-Test (MMST) [German Version], Beltz Test GmbH Göttingen.

[34] Kohn N, Kalbe E, Georg H, Kessler J (2007) Vergleich MMST und DemTect: Spezifität und Sensitivität bei primär kognitiven Störungen. Aktuelle Neurol 34, P672.

[35] World Health Organization (WHO) (1993) The ICD-10 Classification of Mental and Behavioural Disorders - Diagnostic criteria for research, Geneva.

[36] Gauggel S, Birkner B (1999) Validität und Reliabilität einer deutschen Version der Geriatrischen Depressionsskala (GDS). Z Klin Psychol Psychother 28, 18-27.

[37] Hindmarch I, Lehfeld H, de Jongh P, Erzigkeit H (1998) The Bayer Activities of Daily Living Scale (B-ADL). Dement Geriatr Cogn Disord 9(Suppl 2), 20-26.

[38] Logsdon RG, Gibbons LE, McCurry SM, Teri L (2002) Assessing quality of life in older adults with cognitive impairment. Psychosom Med 64, 510-519.

[39] Ware J, Jr., Kosinski M, Keller SD (1996) A 12-Item Short-Form Health Survey: Construction of scales and preliminary tests of reliability and validity. Med Care 34, 220-233.

[40] Geschke K, Fellgiebel A, Laux N, Schermuly I, Scheurich A (2013) Quality of life in dementia: Impact of cognition and insight on applicability of the SF-36. Am J Geriatr Psychiatry 21, 646-654.

[41] Pettit T, Livingston G, Manela M, Kitchen G, Katona C, Bowling A (2001) Validation and normative data of health status measures in older people: The Islington study. Int $J$ Geriatr Psychiatry 16, 1061-1070.

[42] Chalmers K, Badgery-Parker T, Pearson SA, Brett J, Scott IA, Elshaug AG (2018) Developing indicators for measuring low-value care: Mapping Choosing Wisely recommendations to hospital data. BMC Res Notes 11, 163.

[43] Charlson ME, Pompei P, Ales KL, MacKenzie CR (1987) A new method of classifying prognostic comorbidity in longitudinal studies: Development and validation. J Chronic Dis 40, 373-383.

[44] StataCorp (2017) Stata Statistical Software: Release 15. StataCorp LLC, College Station, TX.

[45] Poblador-Plou B, Calderón-Larrañaga A, Marta-Moreno J, Hancco-Saavedra J, Sicras-Mainar A, Soljak M, PradosTorres A (2014) Comorbidity of dementia: A cross-sectional study of primary care older patients. BMC Psychiatry 14, 84 .

[46] Eichler T, Thyrian JR, Hertel J, Michalowsky B, Wucherer D, Dreier A, Kilimann I, Teipel S, Hoffmann W (2015) Rates of formal diagnosis of dementia in primary care: The effect of screening. Alzheimers Dement (Amst) 1, 87-93. 
[47] Kalisch Ellett LM, Pratt NL, Ramsay EN, Barratt JD, Roughead EE (2014) Multiple anticholinergic medication use and risk of hospital admission for confusion or dementia. $J \mathrm{Am}$ Geriatr Soc 62, 1916-1922.

[48] Uusvaara J, Pitkala KH, Kautiainen H, Tilvis RS, Strandberg TE (2011) Association of anticholinergic drugs with hospitalization and mortality among older cardiovascular patients. Drugs Aging 28, 131-138.

[49] Morden NE, Colla CH, Sequist TD, Rosenthal MB (2014) Choosing wisely-the politics and economics of labeling low-value services. N Engl J Med 370, 589-592.

[50] Banerjee S, Hellier J, Dewey M, Romeo R, Ballard C, Baldwin R, Bentham P, Fox C, Holmes C, Katona C, Knapp M, Lawton C, Lindesay J, Livingston G, McCrae N, MonizCook E, Murray J, Nurock S, Orrell M, O’Brien J, Poppe M, Thomas A, Walwyn R, Wilson K, Burns A (2011) Sertraline or mirtazapine for depression in dementia (HTA-SADD): A randomised, multicentre, double-blind, placebo-controlled trial. Lancet 378, 403-411.

[51] Borson S, Frank L, Bayley PJ, Boustani M, Dean M, Lin P-J, McCarten JR, Morris JC, Salmon DP, Schmitt FA, Stefanacci RG, Mendiondo MS, Peschin S, Hall EJ, Fillit H, Ashford JW (2013) Improving dementia care: The role of screening and detection of cognitive impairment. Alzheimers Dement 9, 151-159.

[52] Baicker K, Chandra A (2020) Do we spend too much on health care? N Engl J Med 383, 605-608.

[53] Bott NT, Sheckter CC, Yang D, Peters S, Brady B, Plowman S, Borson S, Leff B, Kaplan RM, Platchek T, Milstein A (2019) Systems delivery innovation for Alzheimer disease. Am J Geriatr Psychiatry 27, 149-161.

[54] Gupta R, Roh L, Lee C, Reuben D, Naeim A, Wilson J, Skootsky SA (2019) The population health value framework: Creating value by reducing costs of care for patient subpopulations with chronic conditions. Acad Med 94, 1337-1342.

[55] Rädke A, Michalowsky B, Thyrian JR, Eichler T, Xie F, Hoffmann W (2020) Who benefits most from collaborative dementia care from a patient and payer perspective? A subgroup cost-effectiveness analysis. J Alzheimers Dis 74, 449-462.

[56] Kim DD, Do LA, Daly AT, Wong JB, Chambers JD, Ollendorf DA, Neumann PJ (2021) An evidence review of low-value care recommendations: Inconsistency and lack of economic evidence considered. J Gen Intern Med, doi: 10.1007/s11606-021-06639-2. 